\title{
Cidades, fronteiras transnacionais e migração na Pan-Amazônia
}

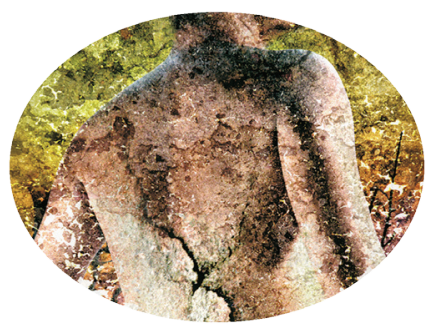

Edna Castro*
Marcel Hareu

\section{Resumo}

Este artigo se propõe analisar os processos de mudança que vêm ocorrendo na fronteira do Brasil com a Guiana francesa, em Oiapoque, do ponto de vista da migração. A perspectiva adotada procura focalizar a compreensão dos sujeitos sociais que transitam nesse espaço transfronteiriço e trazer à visibilidade dimensões pouco estudadas de pequenas cidades que desempenham um papel fundamental na estruturação de regiões distantes e que na atualidade enontram-se sob o foco de novos interesses econômicos e políticos. Trata-se de uma fronteira com significativos fluxos migratórios de brasileiros (Amapá, Pará e Maranhão) que se dirigem aos garimpos do rio Oiapoque e de seus afluentes, e para Caiena, em busca de oportunidades de trabalho, sobretudo na construção civil ou diversos serviços urbanos; e ainda migração para a cidade do Oiapoque que tem seu comércio e serviços ampliados em função de turistas franceses de Caiena. O artigo registra mudanças em curso e descreve o processo de reorganização do território impulsionado pelas políticas desenvolvimentistas do governo brasileiro e das políticas de ultramar da Franca, analisando sua influência nos processos migratórios, como parte de

\footnotetext{
* Doutora em Sociologia pela Ecole des Hautes Etudes em Sciences Sociales, professora da Universidade Federal do Pará, no Núcleo de Altos Estudos Amazônicos/Naea e coordenadora do Grupo de Pesquisa Trabalho, Empresas e Mercados Globalizados/Diretório do CNPq. E-mail: edna@naea.ufpa.br

** Mestre em Ciências Ambientais pela Universidade de Wageningen e mestre em Planejamento do Desenvolvimento pela Universidade Federal do Pará (UFPA/Naea), doutorando da UFPA, em programa do Núcleo de Altos Estudos Amazônicos/Naea, bolsista do CNPq.
} 
processos de integração da Amazônia ao território nacional e sul-americano, e ao mercado internacional.

Palavras-chave: Fronteiras transnacionais; migração; cidades; território; PanAmazônia

\begin{abstract}
This article aims to analyze the processes of change that are occurring on the border between Brasil and Guiana Francesa in Oiapoque the point of view of migration. The perspective adopted seeks to focus the understanding of social subjects passing that area border and bring visibility understudied dimensions of small towns that play a key role in structuring and remote areas that currently are under the focus of new economic interests and politicians. It is a boundary with significant migration of brazilians (Amapá, Pará and Maranhão) which address the mining Oiapoque River and its tributaries, and Caiena, in search of job opportunities, particularly in construction and various services urban, and even migration to the city Oiapoque that has expanded its trade and services in terms of França tourists Caiena. The article records the changes underway and describes the process of reorganization of the territory driven by the development policies of the brazilian government and politics of France's overseas, analyzing their influence on migration processes, as part of the integration processes of the Amazon territory and south american and the international market.
\end{abstract}

Keywords: Transnational borders; migration; cities; territory; Pan-Amazon

\title{
Introdução
}

O objetivo deste artigo é analisar as mudanças contemporâneas que estão ocorrendo na fronteira do Brasil com a Guiana Francesa, no município de Oiapoque, a partir das migrações que constituem elementos constitutivos e reflexos dessas mudanças. Procura-se responder o que as trajetórias históricas recentes de migrantes podem revelar sobre o contexto atual de processos de integração, controle, investimentos e abandono do município em questão.

A Amazônia, em sua dimensão continental, passa atualmente por um 
acelerado processo de transformação econômica e social, com efeitos sobre a urbanização como se pode observar nas dinâmicas intraurbanas, demográficas e no aparecimento de novos povoamentos. Esse processo verifica-se nas fronteiras de todos os países pan-amazônicos, embora com intensidade diferente.

Para abordar esse tema lançamos mão de teorias críticas sobre a globalização e a migração, com destaque para a concepção do conceito de fronteira. Pressupõe-se que o estudo das migrações e dos migrantes possa trazer uma leitura e análise diferenciada sobre os processos que produziram historicamente o Oiapoque, além das políticas globalizantes, como a Iniciativa de Integração Regional da América do Sul (IIRSA), na situação atual. Para elaboração deste artigo contou-se com resultados de pesquisas na cidade do Oiapoque $^{1}$ e dados secundários de várias fontes. Descrevemos alguns fluxos de pessoas que estão de passagem, "indo ou retornando", que participaram da construção da ponte sobre o rio Oiapoque ou que trabalham em áreas de garimpo, além de representantes dos moradores indígenas, militares e organizações que trabalham com essa população, tão diversa, em movimento.

Localizada ao norte da América do Sul, praticamente na confluência do Atlântico com o Caribe, a Guiana Francesa é um Departamento Ultramarino Francês. Depende de decisões político-administrativas e econômicas tomadas na "metrópole". Na Franca há categorias distintivas que designam lugares e diferenças internas entre o seu território na Europa e suas colônias de ultramar; são categorias que remetem a estruturas de poder trazidas da relação colonial que persistem, todavia. Essas estruturas coloniais reafirmam os lugares sociais e políticos dos departamentos de "ultramar", e por isso há tensões quanto à possibilidade de autoafirmação e autodeterminação da Guiana, e de Caiena, no sistema político nacional.

A Guiana, vizinha do Brasil, tem grande extensão de fronteira com o Estado do Amapá (limitando-se a leste pelo rio Oiapoque e ao sul pelas montanhas do Tumucumaque) e limitando com o Suriname, a oeste. Sua fronteira com o Brasil ocupa uma área total de $90.000 \mathrm{~km}$. Em 1990, sua população era de aproximadamente 120.000 habitantes, chegando a 160.000 em 2000 e subindo para 205.956 habitantes pelo Censo de 2006. Esse Censo registrou a participação de $37,73 \%$ de estrangeiros no total da população. 


\section{Formação social e econômica do Oiapoque: índios, caboclos, quilombolas, garimpeiros}

A região no norte do Amapá, que hoje é considerada área de fronteira entre o Brasil e a Guiana Francesa, foi uma área em disputa desde a colonização europeia entre a França e o Brasil. Em primeiro lugar pelo domínio, acesso e controle da voz do Amazonas e, posteriormente, pelo domínio dos recursos minerais existentes, com destaque para o ouro:

Uma "definição por decreto" na forma de tratado diplomático, assinado em 1713, indicou como limite de fronteira entre o Brasil e a Guiana Francesa dois toponômios de um mesmo rio (Oiapock ou Vicente Pinzon). Tais toponômios referidos a um dado natural foram objeto de inúmeros outros tratados. Ao dado natural, agregaram-se dados políticos e econômicos. A tentativa de assegurar o domínio territorial e o acesso ao rio Amazonas e o interesse pelas jazidas minerais no Estado do Amapá foram motivos de intensos deslocamentos e "contestados" (SOARES, 1995: 27).

Além do interesse geopolítico estatal, que geralmente é materializado por meio de processos de colonização, ou seja, por migrações estratégicas e presença militar, os dois países vivenciaram, no fim do século 19, processos parecidos de fuga de escravos ou de deslocamento de ex-escravos, depois da abolição da escravidão das plantações e fazendas, no caso do Brasil, na ilha do Marajó, no Pará, e na França, nas ilhas caribenhas. Sem condições de se manter ou sobreviver com dignidade, eles migraram para regiões ainda não tomadas pelo latifúndio e onde havia perspectivas de um futuro melhor, como áreas distantes e com ocorrência mineral, como o ouro, possibilitando a garimpagem. Caboclos e povos indígenas realizaram um mesmo movimento, segundo a pesquisa do Romani (2006):

Ocorreram 'desde o período colonial, inúmeros casos de fugas escravas rumo a possessões da França, ao norte do Brasil, que podem ser compreendidas como fugas para fora em busca da liberdade no outro lado da fronteira brasileira' (BEZERRA NETO, 2000: 232). 
Apesar de terem formado a maioria dos trânsitos, não somente escravos fugitivos percorreram esse caminho em direção à Guiana e à região fronteiriça entre os dois países que era conhecida na época como território contestado. Uma grande população, genericamente chamada de cabocla, realizou o mesmo movimento. Foram os índios de diferentes tribos e provindos da região da foz do Amazonas que emigraram para o norte (p. 14).

Oiapoque é uma região rica em ouro e por isso capaz de mobilizar sonhos e esperanças para encontrar ouro. Pelo seu isolamento em termos de transporte, conexão com grandes centros urbanos e portos, sem latifúndios e propriedades definidas, constituiu-se como uma terra para pioneiros, aventureiros, perseguidos, ou seja, grupos de diversas origens e etnias:

As sucessivas descobertas de ouro na colônia continental francesa, primeiro, em 1863, no Approuague, depois nas terras em litígio do Calçoene, em 1894, e, finalmente, no Ouanary e no Oiapoque, já no ano de 1900, incentivaram todo um conjunto de gente sem alternativa de trabalho nessas sociedades insulares, a debandar-se para a aventura do enriquecimento dourado no continente sul-americano (PETOT, 1986: 102-3; MAM LA FOUCK, 1999 apud ROMANI, 2006).

Sobre o período de 1855 a 1930, Pinto (2006) relata a importância para a formação da população local e econômica da França:

O garimpo é a atividade que impulsiona a economia, atraindo garimpeiros e comerciantes das Antilhas e dos países vizinhos, datando dessa época uma primeira onda de migrantes brasileiros. O garimpo promove também a aproximação com parte das populações quilombolas instaladas na fronteira com a então Guiana Holandesa (atual Suriname) ...cujas habilidades na navegação dos rios eram muito úteis para exploração e escoamento do metal. O desenvolvimento econômico que promove é efêmero, mas favorece o enriquecimento de algumas famílias guianenses, de comerciantes antilhanos e franceses, que 
tendem a fortalecer o processo de urbanização da cidade de Caiena (p. 150).

Inserida na dinâmica da garimpagem e comércio do ouro, outras dinâmicas populacionais ocorreram antes da definitiva presença dos representantes dos Estados nações, militares e administradores. Povos indígenas migraram para a região para ocupar e contestar territórios. Sua presença foi reconhecida nos anos 1920, como relata Musolino (2006):

Em 1927, os trabalhos de Rondon atingem as fronteiras do norte do país e contatam os índios dos rios Oiapoque, Curipi, Urucauá e Uaçá. Desde então o SPI procurou manter uma gestão oficial que assistisse àqueles grupos indígenas com o objetivo de mantê-los no lado brasileiro da fronteira, oferecendo escolarização na língua portuguesa e precário serviço médico-sanitário (p. 56).

Nos anos 1990 as Terras Indígenas Uaça I e Uaça II, Galibi e Juminá, no lado brasileiro da fronteira, foram homologadas e registradas. No lado francês a identidade indígena não é reconhecida como tal.

Os povos indígenas são também migrantes, como alguns trechos da história desses povos, publicada pela Associação dos Povos Indígenas do Oiapoque (2009), podem ilustrar:

Os Galibi Kali’na, oriundos de Mana, na Guiana Francesa, migraram para o lado brasileiro do rio Oiapoque na década de 1950; Os Palikur são os habitantes originários de toda a região. Um grande contingente desta etnia vive na Guiana Francesa, mas a comunicação com as aldeias do lado brasileiro é contínua. Galibi Marworno descendem de vários grupos, dentre os quais Karib, provenientes das Guianas em épocas remotas, além das etnias Marworno e Aruã, hoje extintas enquanto povos diferenciados. Os Karipuna são uma população heterogênea do ponto de vista étnico, prevalecendo famílias de origem brasileira provenientes do salgado paraense e ilhas do Amapá ou de lugares mais longínquos, que se misturaram a uma população local predominantemente indígena. 
A presença dos povos indígenas, garimpeiros, caboclos e quilombolas na região de Oiapoque, principalmente a partir do final de século 19 e no século 20, se relaciona com os interesses dos governos do Brasil e da França em assegurar seu domínio sobre o território e seus recursos naturais. Além de destacar militares para a região, a "incorporação" dessa população como nacionais se tornou uma estratégia importante. Ela era na sua origem muito diversa e sem forte identificação nacional, tendo suas identidades coletivas baseadas em histórias que envolviam ilhas caribenhas, a ilha do Marajó e a região ao norte do rio Amazonas.

A presença militar no lado brasileiro se materializou de forma mais efetiva depois dos anos 1920, especificamente na Clevelândia do Norte, a 20 quilômetros da cidade de Oiapoque. Esse lugar foi projetado para ser uma colônia agrícola, mas tal projeto fracassou. Em seguida se tornou, segundo Romani (2003), uma colônia penal, um verdadeiro campo de concentração, onde presos comuns e presos políticos foram confinados pelo governo de Arthur Bernardes para colonizar a fronteira e silenciar a oposição mais combativa ao seu regime: "Dos 946 presos lá internados entre 1924 e 1927, 491 morreram, ou seja, mais da metade" (ROMANI, 2003: 117). Atualmente encontra-se em Clevelândia a base da 1. Companhia de Fuzileiros de Selva, unidade do Exército Brasileiro encarregada de guarnecer a fronteira com a Guiana Francesa (KRONENBERG, 2011).

\section{Cidades e fronteiras na Pan-Amazônia no início do século 21}

Uma análise crítica sobre o lugar das cidades em fronteiras a partir de um enfoque comparativo entre cidades pan-amazônicas aponta para a constituição de redes globais, formas de agregação regional e a redefinição do papel das cidades em áreas de fronteira política, envolvendo processos e ações estatais para consolidar iniciativas de ordenamento territorial e os novos conflitos nessas cidades. A perspectiva das políticas governamentais é de integração definitiva dessas áreas ao mercado nacional, internacional, e a constituição de corredores transfronteiriços de transporte de mercadorias (CASTRO, 2009; 2010).

As relações sociais e econômicas na fronteira organizam-se em redes 
que funcionam com a mesma lógica, mas em um mercado predominantemente informal, clandestino, ilegal e diverso, que combinam certamente o formal e o informal, o legal e o ilegal, de forma híbrida, como assinala Machado (2000). Contudo, o fundamento da análise distancia-se desses antagonismos ou oposições binárias, pois a dinâmica e a complexidade dessas redes respondem seguramente pela manutenção das estruturas nas relações de troca, o que fica bem explícito quando se analisam as práticas de agentes do campo econômico, certos segmentos como os da mineração, da pesca, da pecuária, da exploração madeireira e na produção agrícola. Notadamente vinculados a um mercado informal nas fases de captura (pescado) ou de extração (madeira), esses setores estão inseridos, ao mesmo tempo, no sistema de mercado regido por uma dinâmica globalizada.

Cabe lembrar que o território brasileiro é bem maior do que poderia ter sido caso as populações locais não avançassem para além dos limites legais definidos nos acordos bilaterais. Diversos litígios de limites com países vizinhos resultaram de lutas territoriais em pontos avançados da fronteira, obrigando à revisão dos acordos diplomáticos. Efetivamente, os desdobramentos dos conflitos por limites entre o Brasil (Estado do Acre), a Colômbia e o Peru; entre o Brasil e a Venezuela (Estado de Roraima); Brasil e Bolívia, e entre o Brasil e a Guiana Francesa (Estado do Amapá) acabaram por dar origem, não por acaso, aos territórios federais, como espaços de controle e de presença do Estado.

Tensões de fronteira sempre envolvem os agentes que atuam no território e os modos de apropriação e de comercialização dos recursos. As tensões nas fronteiras amazônicas entre o Brasil e a Venezuela foram motivadas nos anos 70 pela chegada de brasileiros interessados na exploração de madeira e na sua exportação para a Venezuela. Nos anos 80, tornaram-se mais tensas essas relações pelo avanço de frentes garimpeiras subindo o rio Oiapoque e ocupando garimpos no território francês. E chegaram também mais a oeste, no rio Orinoco, palco de conflitos com os índios Yanomami. Atualmente, há conflitos em inúmeros pontos da fronteira com a Venezuela e também com a Bolívia, a República da Guiana, a Guiana Francesa e Suriname. Longe de recrudescerem, atualizam-se, pelo encontro crescente dos grupos nos seus lugares e de outras frentes de atores e mercados - arrozeiros, pecuaristas, sojeiros, empresas mineradoras e comerciantes - de um lado e, de outro, 
instituições estatal-militares, policiais e de órgãos executivos referidos a terra e ao uso dos de recursos naturais).

Há simultaneidade de dinâmicas nos diferentes Estados da Amazônia. O exemplo da demarcação da Terra Indígena Raposa/Serra do Sol no extremo norte de Roraima, e que ganhou enorme visibilidade nacional e internacional, revela processos de desterritorialização e reterritorialização, mais correntes do que se imagina. As fronteiras à altura das cidades de Oiapoque (Amapá) e de Bonfim (Roraima) registram, na atualidade, conflitos entre índios e garimpeiros, agravados pelo afluxo demográfico e pelos novos atrativos da economia informal e/ou ilegal, que encontram nessas áreas oportunidades de crescimento.

A fronteira é um espaço da diversidade linguística, na qual as línguas oficiais, até o presente, têm sido as dos colonizadores: espanhol, português, francês, holandês, inglês, que não podem ignorar a força das línguas indígenas nessas áreas, que ao mesmo tempo ressignificam resistência da cultura, reafirmação do passado/presente e de suas raízes. Também é o lugar de controle dos Estados nacionais e, em pontos determinados, esse controle do Estado moderno é realizado mediante carteira de identidade. Uma visão da diversidade resulta de comparação das tradições alimentares; dos saberes sobre a natureza e dos usos coletivos, materiais e simbólicos, das trocas musicais etc. Em diversos casos não existem barreiras físicas, como Letícia e Tabatinga; outras têm fortes interdições, como o acesso do Brasil à Guiana Francesa, embora no sentido contrário não seja o mesmo procedimento rígido de controle e de impedimento à mobilidade. O rio é quase sempre o caminho mais percorrido nessa imensidão entre fronteiras ou para entrar nos meandros da floresta, através de braços, igarapés, furos e chegada à Caiena (CASTRO, 2012).

As fronteiras são espaços etnicamente plenos e, por isso, as cidades de fronteira na Amazônia têm a particularidade do multiculturalismo, da diversidade de etnias e culturas. Dimensões essas que recentemente têm sido incorporadas na compreensão do universo urbano da Pan-Amazônia.

\section{Oiapoque e Saint-George/Caiena: redes e globalização}

A dinâmica singular de fronteira faz parte do cotidiano das pessoas, 
com suas relações particulares com o território e as redes de troca que se espalham até os países do Caribe. As relações de comércio entre Oiapoque e a pequena cidade guianense Saint-George, do outro lado do rio, são restritas se considerarmos o que é oferecido no comércio de Saint-George. São intensas, porém, considerando o fluxo de guianenses e de brasileiros que vêm de Caiena, a 180 quilômetros, para fazer as compras na cidade de Oiapoque, passar finais de semana, ou em trânsito para outros lugares do Brasil. Observa-se desde o final do século 20 o aumento dos interesses em relação a atividades como a pecuária com fazendas que avançam em direção à fronteira política, apesar das Unidades de Conservação ali presentes. Observara-se também a possibilidade de agricultura intensiva, com as primeiras experiências de plantio de grãos na região amapaense de cerrado. Diferentemente de outras cidades brasileiras de fronteira, Oiapoque experimenta um aumento do turismo, com hotéis e pousadas que multiplicaram rapidamente, casas noturnas, bares, restaurantes, o que atrai um turismo de final de semana e ocorrência de turismo sexual e tráfico de pessoas. Vale a comparação dessa área de lazer do Oiapoque com as currutelas de garimpos, numa escala ampliada, ou as áreas em torno de bases militares.

A presença e circulação de homens migrantes, em grupos, militares, garimpeiros numa área de fronteira, pois regida por outras regras e normas do que aquelas que estruturam a vida familiar e comunitária desses homens no seu lugar de origem leva a organização da vida social dominada pelo mercado e pela organização espacial como área de encontro. Em busca de lazer e prazer, mas também de relacionamentos, os homens se deslocam para Oiapoque, enquanto mulheres, travestis e homossexuais organizam sua moradia na cidade para trabalhar e se envolver com essa população masculina. A organização do mercado de sexo é marcada por contradições e sua marginalização legal tem reforçada a presença de redes de exploração e tráfico de mulheres e travestis, pois a perspectiva de lucro na ilegalidade ampliou a dependência do funcionamento desse mercado do crime organizado. Como opera na margem da legalidade, os "maus empresários" ampliam sua atuação para campos do mercado sexual, ainda mais ilegal, envolvendo crianças e adolescentes. Suas práticas de tráfico para dentro da Guiana Francesa têm ganhado mais fôlego com as políticas antimigratórias, que faz que suas redes de tráfico de pessoas se tornarem mais importantes para quem deseja migrar. 
Oiapoque, portanto, como lugar isolado, de difícil acesso e distante dos grandes centros urbanos, no extremo Norte do Brasil, é ao mesmo tempo um lugar intensamente conectado com o mundo globalizado. Um lugar se torna globalizado quando vários processos locais estão conectados com vários outros lugares ao mesmo tempo como uma sociedade em rede, "constituída por redes em todas as dimensões fundamentais da organização e da prática social" (CASTELLS, 1999: II) ${ }^{2}$ e "como as redes não param nas fronteiras do Estado-nação, a sociedade em rede se constituiu como um sistema global" (CASTELLS, 1999: II).

Nessa "globalização", os locais considerados fronteiras entre Estados nação ganham novos significados. Gutemberg Silva (2008: 22), citando Rückert (2007), aponta na mudança de "fronteiras de contenção" e "fronteirasseparação" em "fronteiras-cooperações", na qual a cooperação se refere principalmente a escalas nacionais e transnacionais, para a garantia de uma maior fluidez das operações no mercado internacional e nacional capitalista. Os locais específicos de fronteira, como Oiapoque e Saint Laurent, servem, nesse contexto, como "pontos de passagem" numa lógica de fronteira-rede na qual:

\begin{abstract}
...muitos dos interesses não se projetam efetivamente no lócus da fronteira para as cidades ali conectadas. Tais cidades são utilizadas apenas como nós na rede para integrar pontos maus importantes, o que facilita os fluxos, sobretudo de mercadorias (SILVA, 2008: 25).
\end{abstract}

O fluxo de compra e venda de euro e ouro, nos pequenos portos da orla da cidade, onde atracam as catraias com passageiros vindos de SaintGeorge, e sua oscilação em função de variáveis também locais, interliga essa cidade do extremo Norte do país a redes mais extensas. Esse fato revela a conexão com outras cidades importantes por conta da condição de estar numa fronteira de moeda forte comparativamente ao real, e interpondo, portanto, Brasil e Comunidade Econômica Europeia. Dessa forma, constitui um eixo de relação entre cidades desses dois mundos (Macapá, Belém, São Paulo etc.), pois o mercado de euro e ouro local é movido por interesses localizados nessas cidades. 


\section{Políticas macro e a Iniciativa de Integração Regional da América do Sul/ IIRSA}

As mudanças verificadas na economia mundial, com a reestruturação da produção e dos meios de comércio, e com a crescente financeirização e globalização, alteraram o padrão tecnológico e o de gestão, importantes para os fluxos de mercadorias, de serviços e, sobretudo, de informações. Elevaram a outros modos de articulação dos países, como a formação de blocos regionais.

No caso da IIRSA, são dez eixos que recobrem o continente sulamericano. Três deles estão direcionados para a Pan-Amazônia e atendem ao interesse pelas vias de transporte - estradas, ferrovias, rios - do Atlântico ao Pacífico. O eixo Escudo Guianense, denominação dada à região formada pela parte oriental da Venezuela, pelo extremo Norte do Brasil (Estados do Amapá e Roraima), pelas Guianas e pelo Suriname, elege cidades como referência na logística de transporte e serviços: Manaus, Caracas, Macapá, Georgetown, Paramaribo, Boa Vista, Caiena, Santa Elena de Uiarén, Ciudad Bolivar e Ciudad Guayana.

A análise de fluxos vincula os grandes eixos de transporte interno no país aos projetos na fronteira com outros países. É o caso da ponte sobre o rio Oiapoque, ligando o Brasil à Guiana Francesa e abrindo, a partir dela, outra saída para o Caribe. Entende-se, nessa ótica, que se está diante de um movimento ao mesmo tempo rápido e simultâneo, em múltiplas direções, o que se configura em um novo espaço de fluxos (CASTRO, 2012).

Para efeito dos interesses percebidos na concepção do planejamento, seja dos Estados Nacionais (Brasil e Franca), seja da Iniciativa de Integração da Infraestrutura da América do Sul (IIRSA), pois o Escudo Guianense é considerado um dos eixos de desenvolvimento (CASTRO, 2010; BRASIL, 2008; IIRSA, 2004), podem-se aguardar processos de mudanças sociais, políticas e econômicas em cadeia, como já observado, para o lado brasileiro, pela construção da ponte sobre o rio Oiapoque ligando aquelas duas cidades.

A IIRSA é a materialização da necessidade do mercado capitalista de integração e articulação física dos mercados na América do Sul para acessar os recursos naturais, diminuir os custos de transporte e aumentar a velocidade dos processos produtivos e circulação dos produtos. Uma iniciativa elaborada e gestada longe de Oiapoque e até do Estado do Amapá, nos centros do poder 
econômico e político, nacional e internacional. A população e a realidade local na região de intervenção da IIRSA, como os dois lados da fronteira e Oiapoque, são desconsideradas como foco de políticas públicas e investimentos. As populações são ausentes nessa transformação do significado da fronteira tanto como sujeitos quanto como destinatários, pois "a aposta não é a ocupação de áreas, mas a preocupação de ativar pontos e linhas, ou criar novos nódulos que facilitem os fluxos" (SILVA, 2008: 25) e "tanto a rodovia quanto a ponte sobre o rio Oiapoque são empreendimentos associados a uma outra lógica, voltados fundamentalmente ao atendimento de demandas externas àquelas localidades" (SILVA, 2006: 145).

\section{Migrações recentes e fronteiras}

Em termos numéricos, a dinâmica populacional histórica do município de Oiapoque é difícil de ser quantificada, até porque, como a fronteira entre os dois países, não foi ela efetivamente firmada e "controlada", a população perambulava entre os dois territórios, o que os povos indígenas ainda fazem e os garimpeiros por força da dinâmica garimpeira continuam fazendo.

Os Censos do IBGE (Tabela 1), desde 1950, mostram um crescimento gradual da população do município de Oiapoque até 1980, tornando-se exponencial de 1980 até 2010. O Censo de 2010 traz algumas novas informações sobre a dinâmica populacional de Oiapoque e migração para Guiana Francesa. A migração brasileira para Guiana Francesa, registrada pelo IBGE e que passa por parte pelo município de Oiapoque, além de viagens diretas de barco e avião, tem origens específicas e composição de gênero diferenciada.

\begin{tabular}{l|l|l|l|l|l} 
Origem: Pais & Brasil & \multicolumn{4}{l}{} \\
\hline Estado & & Amapá & Maranhão & Pará & \\
\hline Municipio & & & & & \\
\hline Migrantes brasileiros na Guiana Francesa & 3822 & 1093 & 1109 & 1186 & 81 \\
\hline$\%$ mulheres entre os migrantes & $44 \%$ & $56 \%$ & $25 \%$ & $50 \%$ & $48 \%$
\end{tabular}

Fonte: IBGEl(2011)

Tabela 1 - Crescimento da população do município de Oiapoque

Fonte: IBGE, 2011 
Sendo Oiapoque o município de fronteira com Guiana Francesa, o número de migrantes daquele município para Guiana Francesa é muito baixo. A emigração se organiza a partir de redes sociais que partem do Pará, Maranhão e outros municípios no Amapá. As redes que envolvem Maranhão organizam uma migração predominante masculina, o que sugere redes migratórias voltadas para o trabalho garimpeiro e de construção civil, profissões dominadas pela força de trabalho masculina, além de não apontar para dinâmicas de migração de famílias e reagrupamento familiar.

Esses dados reforçam a ideia de Oiapoque como município de passagem, mas também como município de destino, pois $50 \%$ da sua população não nasceu no município, enquanto no Brasil esse percentual é de 33\% e no próprio Amapá é 40\% (CENSO, 2010).

A migração de brasileiros para a Guiana Francesa cresceu nas três últimas décadas como mostram Pinto e Castro (2008). Desde o início dos anos 80, no auge da construção das instalações da cidade de Kourou, ${ }^{3}$ a saída de brasileiros para a cidade de Caiena tornou-se uma opção para milhares de trabalhadores nas cidades próximas e em áreas rurais. Nesse mesmo período observam-se movimentos migratórios que eclodem em todo o país em busca de oportunidades de trabalho em outros países, com destino aos Estados Unidos, a países da Europa e Japão que representam os fluxos mais importantes, embora não exclusivos. Esses fenômenos devem ser vistos sob uma perspectiva transcultural, intensificando-se a presença de migrantes de nações menos industrializadas nos países considerados ricos. Vale ressaltar que a migração temporária é justamente o que esses países desenvolvidos necessitavam, principalmente para suprir postos de trabalhos em setores com pouca qualificação profissional, caracterizados por baixos salários e reduzidas perspectivas de ascensão social.

As migrações em geral, principalmente as de escala intercontinental, fazem parte de um processo mais amplo resultante de vários fatores, entre eles a compressão do tempo e do espaço com a intensificação das relações globalizadas. Assim, famílias e grupos deslocam-se por meio de fronteiras geográficas, históricas e étnicas, e experimentam processos em massa de desterritorialização.

O trabalho e a comparação de suas condições no Brasil e na Guiana Francesa são o tema principal nas discussões entre migrantes brasileiros em 
Caiena, como mostram Castro e Pinto (2008), acrescentando que a migração de trabalho se transforma em migração de população com reagrupamento de suas famílias (CUCHE, 1999). Migrantes vinculam os lugares de origens e destinos, construindo realidades transnacionais que não podem ser estudadas como realidades desconectadas. A migração não é, somente, uma questão de integração e novas convivências, mas também de articulações, vinculações e redes sociais, ou seja, trata-se de relações entre lugares, regiões e países, entre sujeitos sociais, políticos e econômicos.

A maioria dos trabalhadores brasileiros no mercado de trabalho na Guiana Francesa desenvolve atividades manuais ou braçais e não intelectuais. Brasileiros revelam certa decepção com as possibilidades de mobilidade no mercado de trabalho e ascensão a postos mais valorizados, ainda que tenham sua situação legalizada. Os postos mais importantes na esfera da decisão política são reservados a franceses que vêm da Franca, representantes de ministérios ou de outros órgãos nacionais, com participação menor de franceses guianenses.

A remuneração do trabalho e a seguridade social são os dois motivos principais apresentados pelos trabalhadores brasileiros para permanecerem em Caiena. Mas ficam divididos quando avaliam outros itens que dizem respeito, sobretudo as diferenças com a cultura brasileira (PINTO; CASTRO, 2007). Relatam casos de trabalhadores que reafirmam que vão voltar para o Brasil, no entanto as condições materiais de existência adiam seguidamente essa decisão. Consideram que o ato de deixar o Brasil significa a saída de um país marcado por profundas desigualdades sociais e ao mesmo tempo o afastamento de uma região (Amazônia) com ausência mesmo de políticas públicas básicas.

Os imigrantes legalizados estão incluídos na rede assistencial que é melhor que a brasileira. Todos os trabalhadores pagam uma espécie de seguro saúde, e dessa forma dispõem de bons serviços nessa área. Na realidade, são esses direitos que faltam no Brasil os responsáveis pelas dúvidas e receios que os migrantes brasileiros sentem em retornar ao país. Além disso, esses serviços básicos alimentam o sonho de milhares de desempregados, criando uma expectativa de quem conseguir um emprego na Guiana Francesa "está feito na vida" (PINTO; CASTRO, 2008).

Desde final dos anos 1970 as sociedades experimentam enormes mudanças nas formas de produzir e emerge daí uma nova divisão internacional de trabalho (BOYER, 2006) no contexto da emergência de um novo regime 
de acumulação e de modo de regulação (HARVEY, 1998). O contexto é de uma economia globalizada. E esta acaba por determinar novas dinâmicas no mercado de trabalho e na mobilidade do trabalhador que passa a se reger também por princípios de flexibilização do trabalho, seguindo os processos produtivos e as novas plantas industriais que, deslocalizadas, geram fluxos de pessoas em movimentos migratórios que atravessam fronteiras geográficas, políticas e culturais. As migrações são materializações que revelam conflitos e disputas pelas formas e pelo direito de ocupação e uso de territórios no contexto da globalização.

No contexto de fluxos migratórios as diversas teorias e abordagens apontam para algumas questões que ajudam a analisar e interpretar dinâmicas sociais que envolvem deslocamentos de pessoas, saídas, chegadas, retornos e passagens. Algumas condições, segundo Sassen (2010), "estruturam" fluxos migratórios entre dois espaços: antigos laços coloniais, a dominância econômica, espaços transnacionais, a atividade militar, a exportação organizada de trabalhadores, os efeitos devastadores da globalização das economias nos países pobres e o desenvolvimento de complexos turísticos de massa. Outros fatores específicos que podem tornar a condição de pobreza em estímulo à migração são, segunda a autora, o recrutamento direto por empresas ou governos; a formação de comunidades de migrantes que começam a operar como redes de migração; a interdependência crescente entre países; a exportação organizada (legal ou ilegal) de trabalhadores. Só existem fluxos migratórios entre lugares que também estão conectados por meio de outras dimensões históricas, econômicas, culturais e políticas (SASSEN, 2010).

Embora a fronteira possa ser um fator de integração, na medida em que é uma zona de interpretação mútua e de constante manipulação de estruturas sociopolíticas e culturais distintas, cada lado de uma fronteira apresenta estruturas culturais, sociais, econômicas, políticas e demográficas diferenciadas (SOARES, 1995). Os migrantes são sujeitos que interligam lugares de origem e destino, interferem com sua ausência na origem e com sua presença no destino nas dinâmicas locais e questionam permanentemente com sua presença a ordem estabelecida e até a noção de nação (SAYAD, 1998). Suas trajetórias não são aleatórias e os tratamentos diferenciados dados pelas autoridades locais e nas políticas públicas refletem interesses e conflitos concretos. Suas diferentes histórias, identidades, culturas e perspectivas retratam conflitos pelo território, 
tornando-se ora aliado dentro de projeções hegemônicas, ora obstáculos para elas.

Reconhecendo que migrantes não abandonam suas origens, mas articulam e mantêm contatos entre os vários espaços de vivência por meio das redes familiares e sociais, os migrantes se tornam sujeitos transnacionais, produzindo novas identidades e realidades.

A realidade na fronteira entre Oiapoque e Saint Laurent não se resume à sua condição de passagem ou ponto numa fronteira-rede, pois há extensos territórios envolvidos e vários grupos sociais e pessoas em disputa pela ocupação, uso, apropriação e domínio deles. A nova condição de fronteirarelação e ponto de passagem no momento histórico da configuração da globalização como parte da IIRSA influencia nesse processo de des-reterritorialização local. As pessoas que moram e passam pelo Oiapoque fazem parte desse processo, porém sem que elas e os poderes constituídos locais estejam preparados para se posicionar estrategicamente nessa arena (SILVA, 2006). Todas reconhecem que, além de vantagens em termos de transporte, a nova condição da "fronteira-Oiapoque" trouxe mais conflitos e violência e que os benefícios futuros não serão divididos igualmente entre os envolvidos.

\section{Novas e antigas dinâmicas no município de Oiapoque}

Em Oiapoque, um "projeto global", de investimentos na infraestrutura para a aceleração da produção, facilitará o acesso aos recursos naturais e circulação de mercadorias, também reúne dois projetos (históricos) de disputa pela hegemonia política sobre esse projeto na América do Sul. De um lado, o projeto dos países da América do Sul, liderado pelo maior interessado que é o Brasil, e o projeto da França que se articula com interesses da Comunidade Econômica Europeia de acesso aos recursos e mercados sul-americanos. Em ambos os casos, o interesse geopolítico é expresso em documentos oficiais, acordos bilaterais e por investimentos concretos. A construção da ponte sobre o rio Oiapoque pode ser mais simbólica do que prática, por materializar uma parceria e abrir a porta para outras formas de cooperação, como o Centro Franco-Brasileiro da Biodiversidade Amazônica e o Protocolo de Cooperação para o Desenvolvimento Sustentável do Bioma Amazônico (REIS, 2010).

Nesse contexto, a IIRSA parece apontar as diretrizes e projetos. Mas a 
dinâmica entre os dois países vai além dessa iniciativa. Vários acontecimentos a ambos os lados da fronteira têm influenciado os fluxos migratórios no município de Oiapoque nas últimas décadas: os processos diretamente vinculados aos interesses europeus, como a construção das instalações em torno da base espacial na cidade de Kourou e a política europeia e francesa antimigratória. Há também questões relativas a políticas internas de cidadania (como a união familiar para migrantes), processos macroeconômicos como a valorização do euro em relação ao real, políticas de restrição de acesso ou exploração de recursos naturais, como o fechamento dos garimpos no Oiapoque no lado brasileiro e a repressão à garimpagem no território francês. Cabe ressaltar ainda a homologação das terras indígenas no território brasileiro, pois a Franca, na tradição nacional-colonialista, não reconhece o direito territorial e identitário de povos indígenas.

As migrações nesse contexto podem ser consideradas migrações internas de expansão de fronteiras internas e novas migrações internacionais (ARNOUCK, 2000), dois movimentos migratórios que têm Oiapoque como espaço estratégico, sendo um envolvendo-o como centro da vida de migrantes, principalmente ligada à atividade garimpeira, e outro como lugar de passagem, uma barreira e possibilidade de realização de uma migração metropolitana.

A essa observação sobre o caráter das migrações precisa ser acrescentada o fato de que as migrações não obedecem simplesmente às lógicas econômicas e que migrações, antes de um simples deslocamento de mão de obra, envolvem sujeitos muito diversos com motivações diversas. Migrante também não é uma identidade, mas a condição de migrante faz parte da construção de identidades múltiplas, que envolvem posicionamentos em relação ao sexo, gênero, raça, classe, nacionalidade, geração, profissão, orientação sexual etc. Há importantes diferenças entre a realidade migratória entre o Brasil e a Guiana vivenciada por mulheres e homem, por pessoas de classe média e de classes trabalhadoras, por negros, indígenas e brancos, por brasileiros e surinameses e por todas as combinações possíveis dessas condições identitárias. Suas tramas são conectadas por intermédio do "nó" nas redes chamado Oiapoque e cujas decisões e estratégias são formadas na complexa interação de informações, projetos de vida, redes familiares e de conhecidos, atividades econômicas, forças e políticas repressivas ou de incentivo, conflitos interpessoais, interesses políticos e econômicos. 
Além da base Kourou, como referência para a migração, a garimpagem tem sido a atividade constituinte por excelência da habitação e dinâmica econômica e social no município de Oiapoque, como os relatos históricos mostram. Nos anos 80 ocorreu um grande movimento migratório para o próprio município de Oiapoque para garimpar, como relata Pinto (2006):

\begin{abstract}
Na década de 1980, dezenas de dragas e motores, ligados dia e noite, extraíam pedras e cascalhos do rio em busca de ouro. Centenas de homens trabalhando embaixo do rio e inúmeros barcos, em frente ao município, davam a exata dimensão da luta pelo Eldorado. Mas com a mesma rapidez que o ouro apareceu às margens da cidade, ele sumiu. Milhares de garimpeiros, com a diminuição da produção aurífera em toda a região do Amapá, resolveram procurar o metal precioso em outras áreas de difícil acesso na selva amazônica, inclusive dentro do território francês e no Suriname (p. 171).
\end{abstract}

Outros fatores importantes também pararam a intensa dinâmica garimpeira, pois moradores relatam que a garimpagem foi proibida, o que é confirmado por Oliveira (2010) no Diagnóstico do setor mineral do Estado do Amapá (2010), que justifica a proibição em decorrer da criação do Parque Nacional Montanhas Tumcumaque. O governo brasileiro já tinha experiências com o fechamento de áreas garimpeiras e as consequências, ou seja, a migração maciça da comunidade garimpeira para outras regiões amazônicas. Havia, portanto, a consciência de que, com muitas informações e garimpos em atividade na Guiana Francesa e no Suriname, uma nova dinâmica garimpeira de brasileiros iria se focar nesses dois países.

Observam-se, a partir dessa nova realidade, conflitos mais abertos, que também expressam o choque de frentes com interesses antagônicos, como o avanço de grupos garimpeiros e/ou empresas de mineração sobre terras indígenas. O garimpo no rio Oiapoque, em terras guianenses, tem sido palco de confronto entre grupos de brasileiros que trabalham em garimpos no rio Oiapoque e a Gendarmerie Nationale, responsável na Guiana pela guarda e vigilância da fronteira (CASTRO, 2011).

A realidade transfronteiriça não se resume também somente ao garimpo e ao mercado de construção e serviço em Caiena e Kourou. A criação de 
reservas naturais se enquadra na organização do espaço dentro de lógicas do capital, do Estado e do movimento ambientalista:

A preocupação com a conservação dos recursos naturais e da biodiversidade tem levado a maioria dos países a ter um olhar estratégico em relação ao patrimônio natural, e também a criação de medidas legais para proteger ou regular o uso deste patrimônio. A criação em 2002, do Parque Montanhas do Tumucumaque, coube ao exército destacar um pelotão para a vila Brasil, uma pequena comunidade de comerciantes estabelecidos antes da criação do parque, uma vez que órgãos estaduais e federais não disponham de pessoal... para a fiscalização e proteção da área (CARMO, SOUZA, 2010).

A demarcação de terras indígenas no lado brasileiro e a não demarcação no lado francês têm provocado vários movimentos migratórios, por interesses geopolíticos e econômicos nacionais e na disputa pela identidade e território pelos povos indígenas. Há uma "disputa" em torno da nacionalidade e pertencimento dos povos indígenas que habitam a área de fronteira de Oiapoque, no qual as políticas de reconhecimento de terras indígenas pesam para o lado brasileiro e os benefícios sociais como cidadão francês para o lado francês:

\footnotetext{
No Brasil chegou-se a propor o papel dos indígenas como guardiões de fronteira nacionais, em lugares onde o exército não pudesse estar presente. $\mathrm{E}$ mais, passou-se a exigir o serviço militar dos indígenas brasileiros, principalmente daqueles que habitam regiões da fronteira e passaram a morar nas zonas urbanas da fronteira, quer sejam na Guiana nos municípios de Saint Georges ou de Ouanary, quer sejam no Amapá no município de Oiapoque (MUSOLINO, 2006: 56).
}

Se há, a um lado, a força do euro e do sistema social, ao outro lado, há a negação ou a exterminação de uma cultura e identidade própria no lado francês, pois as comunidades indígenas na Guiana têm de se adequar à legislação constitucional francesa, que os torna cidadãos franceses com 
obrigações e direitos completamente estranhos ao seu tradicional modo de vida (MUSOLINO, 2006: 62).

Alvaro Musolino (2006) mostra que o povo Palikur, que vive aos dois lados da fronteira, tradicionalmente manteve uma relação migratória com Caiena via rota marítima, a qual também funcionava como principal via de escoamento da produção rural do município. A construção da estrada que liga Saint George a Caiena tirou a importância desse meio de conexão. Mas como outros brasileiros, os Palikur do lado brasileiro têm migrado para trabalhar na construção civil e na produção agrícola no lado francês, muitas vezes empregados por produtores rurais Palikur franceses (MUSOLINO, 2006).

Observa-se que a migração que envolve esse povo indígena tem uma garantia de retorno a terra indígena no Brasil, onde é pleno cidadão e pode investir. A territorialidade garantida faz que essa modalidade migratória, apesar de se direcionar às mesmas atividades de migrantes brasileiros não indígenas, precisa ser analisada de forma diferente, tanto no significado para os povos indígenas quanto dentro das estratégias dos dois Estados nações.

As políticas em relação aos povos indígenas e a integração política e econômica da América do Sul são duas diretrizes e investimentos estatais para dominar e regularizar o território de fronteira que envolve Oiapoque. Acrescente-se a estas as políticas migratórias propriamente ditas do Brasil e da França.

O Brasil, a partir dos anos 1990, tem percebido a importância de uma política de apoio às comunidades brasileiras no exterior, decorrente da importância das remessas, mas também em termos geopolíticos, pois as redes sociais envolvendo brasileiros constituem pontos de fluxos de informações, produtos, recursos e poder político.

Muitas políticas migratórias são formuladas e implementadas a partir de interesses políticos e econômicos explícitos e ocultos, como atrair mão de obra qualificada, marginalizar a posição de trabalhadores migrantes em outros setores da economia para baixar salários e minimizar reivindicações de direitos, apontar pessoas de outras nacionalidades como causa de problemas econômicos e sociais, formação de certa composição de raça e etnia da população, ampliação do controle do Estado sobre a população em geral, estimular o crescimento da população, entre outros.

França, como membro da União Europeia, tem adotada uma política 
migratória seletiva, atraindo cientistas, artistas, jogadores e empresários brasileiros e reprimindo a imigração de pessoas de classe trabalhadora, a partir de reforçados controles nas fronteiras e a perseguição, prisão e deportação de migrantes não documentados. Para a Guiana Francesa a França tem implementado uma política específica de exigência de vistos para brasileiros para sua entrada no território, diferenciada da política de entrada na França metrópole, medida justificada pelo grande fluxo de brasileiros para Guiana Francesa, considerada fronteira externa da União Europeia, que comprometia os compromissos assumidos pela França.

Essa política migratória francesa se traduz na produção do migrante ilegal, condição na qual se encontra a maioria dos brasileiros na Guiana Francesa. Essa condição serve para afirmar a França como Estado nação, definindo quem é e pode ser francês e ter direitos de cidadania e quem não é e não pode ser. Migrantes brasileiros não documentados vivem, por essa política, permanentemente sob a pressão de poder ser deportados, escondendo-se e fugindo da polícia francesa, uma insegurança que abala a saúde psicológica e as possibilidades de investir e acessar serviços. As perseguições e deportações concretas são, muitas vezes, acompanhadas por atos de intimidação e violência, como a apropriação e queima dos pertences das pessoas, humilhações, violência física e até morte. São forçadas a viver uma vida clandestina com cada vez menos perspectiva de acessar a cidadania francesa. Há uma ligeira diferença para homens e mulheres. Com a presença de um contingente grande de homens franceses sem família ou companheiras, a presença das mulheres brasileiras é mais tolerada ou negociada.

A perseguição dos "ilegais" parece servir para marginalizar os direitos e reivindicações no mercado de serviços e construção civil nas áreas urbanas e nos garimpos para assegurar as áreas de minério para empresas capitalistas para sua futura exploração. A presença maciça dos brasileiros parece criar uma ameaça na disputa pelos territórios ao domínio francês, como uma colonização não organizada, disfarçada.

Oiapoque, nesse cenário, representa tanto um lugar de chegada de deportados, que não são levados por avião para Manaus, Macapá ou Belém, quanto um porto de segurança para muitos garimpeiros que trabalham na Guiana Francesa. Naquele lugar eles não são clandestinos, ilegais e perseguidos. Apoio explícito por parte do governo brasileiro a essas populações quase não 
há, até por poder ser interpretado como investidos na colonização e ocupação brasileira da Guiana Francesa numa área que continua sendo disputada e cuja integração contraditória não se dá somente por meio de obras infraestruturais, mas principalmente por migrantes.

Oiapoque também tem recebido imigrantes internacionais, principalmente franceses, que atuam no comércio local, participando na movimentada área de hotéis, bares e clubes, muitas vezes casados com mulheres brasileiras. Como sua presença não é problematizada pelo Estado Brasileiro, eles vivem uma condição "tranquila" de migrante ou de turista.

\section{Considerações finais}

As sociedade têm passado por profundas transformações a partir do último quartel do século 20, com mudanças na globalização que têm alterado o funcionamento das sociedades modernas, notadamente no mundo do trabalho, da produção, da comunicação. E também noções como as de tempo e de espaço. $\mathrm{O}$ avanço desse processo tem posto as sociedade e os indivíduos diante de novos conflitos e desafios de (re)traduzir, continuamente, a experiência social que se conecta a tempos e espaços diversos, em escalas múltiplas, redimensionando a relação local/global, indivíduo/sociedade, sociabilidade/ subjetividade. Os indivíduos e grupos, nesse contexto, passam cada vez mais a interagir com as novas e amplas possibilidades de contato abertas pelo mundo globalizado, incluindo relações transculturais, transnacionais, em diferentes campos (presencial e virtual), alterando processos, identidade e subjetividades.

Em diferentes lugares do mundo mobilizam-se trabalhadores e se deslocam em direção a possibilidades de trabalho em outros países, continentes, criando outros espaços sociais dos processos migratórios. Os trabalhadores são assim crescentemente recrutados em um mercado potencialmente global, transnacional, com contratos celebrados com empresas estrangeiras, em empregos terceirizados por outras empresas, e não poucas vezes de forma clandestina, irregular, ilegal do ponto de vista de leis e de regulamentações sociais.

Essas mudanças, como procuramos demonstrar, alcançam lugares como Oiapoque, cidade de fronteira entre o Brasil e a França. Além de um lugar de passagem, está incluído no projeto de integração econômica e de dinâmicas 
migratórias internacionais metropolitanas, um lugar de disputas territoriais e de identidades, que só podem ser compreendidas na sua complexidade como lugar local e global. Oiapoque é objeto de políticas governamentais estratégicas de dois países, se reorganiza permanentemente em decorrer de conflitos entre populações, residentes e em trânsito, com interesses diferentes que envolvem dinâmicas além do território de Oiapoque.

\section{Notas}

${ }^{1}$ Pesquisa realizada no contexto da Bolsa de Produtividade do CNPq e do Edital Universal/ CNPq, Globalização, mercado e transformações socioterritoriais: o espaço das cidades amazônicas na dinâmica de integração sul-americana. Igualmente a temática foi tratada na Pesquisa do Instituto do Milênio/CNPq Políticas Públicas e Cidadania, coordenado por Peter Spink, da FGV/SP (GT Gestão Pública e Cidadania), tendo participado do recorte municípios de fronteira na Amazônia com os pesquisadores Edna Castro, Manoel Pinto e Joelle Katiussia.

${ }^{2}$ CASTELLS, M. A sociedade em rede. São Paulo: Paz e Terra, 2011.

${ }^{3}$ Cidade localizada a $78 \mathrm{~km}$ a noroeste de Caiena, perto da base de lançamento de foguetes.

\section{Referências}

ARNOUCK, Ronaldo. Brasileiros na Guiana Francesa. Novas migrações internacionais ou exportação de tensões sociais na Amazônia? Lusotopie, 2000, p. 67-78.

ASSOCIAÇÃO DOS POVOS INDÍGENAS DO OIAPOQUE. Plano de vida dos indios e organizações indígenas do Oiapoque. Oiapoque: Apio, 2009, 45 p.

BOYER, Robert. L'économie des conventions 15 ans après: un point de vue à partir de la théorie de la régulation. In: EYMARD-DUVERNAY, François (Dir.). L'économie des conventions: méthodes et résultats. Paris: La Découverte, 2006, tome II, p. 45-66.

BRASIL. Ministério do Planejamento, Orçamento e Gestão. Secretaria de Planejamento e Investimentos Estratégicos. Estudo da Dimensão Territorial para o Planejamento. Sumário Executivo. Brasília, 2008, 85 p.

CASTELLS, M. A sociedade em rede. São Paulo: Paz e Terra, 2011. 
CASTRO, Edna. Integração sul-americana da IIRSA: visão do Estado e dos atores da Pan-Amazônia. In: CARVALHO, José Guilherme; ALMEIDA, Alfredo Wagner B. (Orgs.) O Plano IIRSA na visão da sociedade civil da PanAmazônia. Belém: MPEG, 2009, p. 76-97.

. A Amazônia e seu lugar central na integração sul-americana.

In: NASCIMENTO, Durbens Martins. Internacionalização e defesa nacional. Belém: UFPA, 2010, v. 1, p. 21-45.

; PINTO, Manoel. Estado e políticas sociais em Oiapoque é Caiena. Relatório de Pesquisa. Belém: Naea; São Paulo: FGV, 2008.

CHESNAIS, François. A mundializ̧ação do capital. Trad. Silvana Finzi. São Paulo: Xamã, 1996.

CUCHE, Denys. A noção de cultura nas ciências sociais. Bauru/SP: Edusc, 1996.

HARVEY, David. A condição pós-moderna. São Paulo: Loyola, 1998.

IIRSA. Iniciativa para a Integração da Infraestrutura Regional Sul-Americana. Planejamento Territorial Indicativo. Brasília, DF, 2004.

IBGE http://www.informacoesdobrasil.com.br/dados/amapa/oiapoque/sinopse-censodemografico-2010/

KRONENBERG, A. H. Reportagem Rumos - Rio acima. Na fronteira, 2011. Disponível em <http://www.nafronteira.com.br/blogr/index. php?search=Oiapoque $>$. Acesso em 30 abr 2012.

MARGOLIS, Maxime. Little Brasil: imigrantes brasileiros em Nova York. Campinas: Papirus, 1994.

MUSOLINO, Álvaro Augusto Neves. Identidade e cidadania Palikur na fronteira do Oiapoque e litoral sudeste da Guiana Francesa. 2006, 187 fl. Tese (doutorado em Antropologia Social). Brasília, Centro de Pesquisa e Pós-Graduação sobre as Américas da Universidade de Brasília, 2006.

OLIVIERA, Marcel J. Diagnóstico do setor mineral do Estado do Amapá. Macapá: Iepa, 2010.

PINTO, Manoel de Jesus de Souza. O Fetiche do emprego: um estudo sobre as relações de trabalho de brasileiros na Guiana Francesa, 2007, 273 f. Tese (doutorado em Desenvolvimento Sustentável do Trópico Úmido). Belém, 
Universidade Federal do Pará, Núcleo de Altos, 2008.

PINTO, Manoel; CASTRO, Edna. Mudanças na fronteira: papel do Estado e suas políticas. In: Anais do Seminário Amaz̧ônia e Fronteiras do Conbecimento. Belém: Naea/UFPA, 2008.

REZENDE, T., PINTO, M.. Fenômeno migratório de brasileiros para a Guiana Francesa. PRACS: Revista Eletrônica de Humanidades do Curso de Ciências Sociais da UNIFAP, América do Norte, jul., 2010. Disponível em: http://periodicos.unifap.br/index.php/pracs/article/view/25. Acesso: 2 mai 2012.

ROMANI, Carlos. A história entre o oficial e o lendário: interações culturais no Oiapoque. Antiteses, vol. 3, n. 5, jan.-jun. de 2010, p. 145-169. Disponível em: <http://www.uel.br/revistas/uel/index.php/antiteses>. Acesso em: 20 abr 2012.

SANTOS, B. S. A gramática do tempo. Para uma nova cultura política. São Paulo: Cortez, 2010.

SASSEN, Saskia: A criação das migrações internacionais. In: Sociologia da globalização. Porto Alegre: Artmed, 2010, p. 111-138.

SAYAD, Abdelmalek. A imigração ou os paradoxos de alteridade. São Paulo: Edusp, 1998.

SILVA, Gutemberg de Vilhena. Usos contemporâneos da fronteira franco-brasileira: entre os ditames globais e a articulação local. 2008, 175 f. Dissertação (mestrado em Geografia). Programa de Pós-Graduação em Geografia da Universidade Federal do Rio Grande do Sul, Porto Alegre, 2008.

SILVA, Gutemberg \& RÜCKERT, Aldeman. A fronteira Brasil-França: mudança de usos político-territoriais na fronteira entre Amapá e Guiana Francesa. Confins, n. ${ }^{\circ}$ 7, 2009.

SILVA, José Guilherme Carvalho. Oiapoque: uma parabólica na floresta. Estado, integração e conflitos no extremo norte da Amazônia brasileira. 2006, 152 f. Dissertação (mestrado em Desenvolvimento Sustentável do Trópico Úmido). Naea / Universidade Federal do Pará, Belém, 2006.

SOARES, Ana Paulina Aguiar. Travessia: análise de uma situação de passagem 
entre Oiapoque e Guiana Francesa. 1995, 112 f. Dissertação (mestrado em Geografia). Departamento de Geografia da Faculdade de Filosofia, Letras e Ciências Humanas da Universidade de São Paulo, São Paulo, 1995.

SOUZA, Dario de Jesus Nascimento; CARMO, Ronildo Souza. Geografia politica na fronteira franco-brasileira. Uma análise a partir de Clevelândia do NorteAP, 2010. 60 fl. Trabalho de Conclusão de Curso (Geografia). Faculdade de Geografia, da Universidade Federal do Amapá, 2010.

TOSTES, José Alberto. Oiapoque, terra do nunca. Jornal O Dia, 30 mai 2009. - Planejamento e Desenvolvimento Urbano da Cidade de Oiapoque. Jornal A Gazeta do Amapá, 8 mai 2011. 